\title{
Fair and Square? Social and Spatial Inequalities in Northern Ireland, 2001
}

\section{Malcolm H. Campbell}

To cite this article: Malcolm H. Campbell (2010) Fair and Square? Social and Spatial Inequalities in Northern Ireland, 2001, Journal of Maps, 6:1, 321-329, DOI: 10.4113/jom.2010.1097

To link to this article: https://doi.org/10.4113/jom.2010.1097

\section{Copyright Taylor \& Francis Group, LLC}

+ View supplementary material $\longleftarrow$

巴nublished online: 23 Jan 2012.

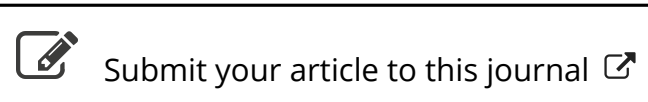

Џll Article views: 131

Q View related articles $\square$ 


\title{
Fair and Square? Social and Spatial Inequalities in Nor- thern Ireland, 2001
}

\author{
MALCOLM H. CAMPBELL \\ Department of Geography, University of Sheffield, Winter Street, Sheffield, S10 2TN, UK; m.h.campbell@sheffield.ac.uk.
}

\begin{abstract}
This paper concerns spatial and social inequalities in Northern Ireland (NI). Social and spatial inequalities are essentially the differences between areas (or individuals) within a given context, for example, within a country. NI is an often omitted region of the United Kingdom in analysis. It has many similarities to the rest of Great Britain, but also some important differences. Using data from the Census of Population in 2001, social and spatial inequalities in Northern Ireland are examined and explored. The areal unit used, the gridsquare, has been underutilised, primarily because it covers only NI. As this resource has been underused, it provides a new perspective for exploring social and spatial inequalities. Using descriptive mapping allows the visualisation of patterns in the data which, when combined with spatial analysis (the Moran statistic) allows quantification of patterns in the data. This approach, combining census data and the gridsquare areal unit, provides a fine grained approach to mapping. A realistic picture of population can be formed using the gridsquare compared with the usual census boundaries. The extent of the map area is NI, every coloured square is equal to one kilometre squared.
\end{abstract}

(Received $18^{\text {th }}$ August 2009; Revised 22 ${ }^{\text {nd }}$ February 2010; Accepted $27^{\text {th }}$ February 2010) 


\section{Introduction}

Social and spatial inequalities are essentially the differences between areas (or individuals) within a given context (for example within a country). This paper explores social and spatial inequalities in Northern Ireland (NI) using data from the 2001 Census of Population at a geographical level which has been underutilised. The areal unit used, the one kilometre Gridsquare (1KGS), has not been widely used for research (Shuttleworth and Lloyd, 2009) primarily because it covers only NI and due to its unusual characteristics. As this resource has been underused, it provides a new perspective for exploring social and spatial inequalities. Using descriptive mapping allows the visualisation of spatial patterns in the data and when combined with spatial analysis, allows for quantification of these spatial patterns. The 1KGS allows a fine grained approach to mapping, as there are 'gaps' in the landscape where there are no people (or too few people to disclose data), meaning more realistic patterns of population can be formed. This is in contrast to standard census boundaries, which do not reflect such subtleties. These differences are interesting to analyse as they can have important implications. For example, if there are concentrations of a particular characteristic in neighbouring areas, or in a particular subgroup of the population. As a smaller peripheral region of the United Kingdom (UK), NI is often omitted in analysis. It has many similarities to the rest of Great Britain (GB), but also some important differences. There has been much research of health inequalities in the UK including gender differences (Rigby and Dorling, 2007; Gjonca et al., 2005; Kruger and Nesse, 2004), differences between socio-economic groups (Acheson, 1998; Black et al., 1980; Davey Smith, 2003; Davey Smith et al., 2002; Ferrie et al., 2002; Graham, 2000; Martikainen and Valkonen, 1996; McCarron et al., 1994; Mitchell et al., 2000; Morris et al., 1994; Townsend and Davidson, 1982; Townsend et al., 1988) and variations between areas at different geographical scales (Boyle et al., 2005; Christie, 2001; Davey Smith et al., 2001; Howe, 1970; Mitchell et al., 2000; Sridharan et al., 2007; Walsh et al., 2008). Many of these studies explore and examine the differences between regions and nations within the UK (Dorling, 1997; Mitchell et al., 2000; Townsend et al., 1988; Walsh et al., 2008) and suggest the existence of a "north-south" divide in health (Shaw et al., 1999) which points to a social and economic divide along similar lines. NI falls on the less favourable 'north' of this divide. NI has escaped the same level of scrutiny as the rest of the UK, i.e. GB, which was observed by Campbell (1993), perhaps because of the distinctive methods of data collection across England and Wales, Scotland and NI or because of the small population of this region. This makes comparing the four constituent countries of the UK somewhat problematic. The result is a paucity of research of NI specific issues (Campbell, 1993) either as a separate entity, or as part of a wider UK study. Furthermore, much of the research conducted in NI has been related to 'the troubles' (Campbell, 1993) and its associated problems (O'Reilly and Stevenson, 1998), with much less research on other important issues, such as health inequalities, compared to the rest of the UK. Examples of health inequalities research in NI include the issue of selective migration (O'Reilly and Stevenson, 2003), 
the negative effects of fuel poverty on health (Shortt and Rugkåsa, 2007) and how segregation adversely affects mental health (French, 2009). Moreover, work by O'Reilly et al. (2001) comparing the Irish cities of Belfast and Dublin showed "selective migration has played a significant part in explaining the changing patterns of health around these cities" (p.355). In order to address this paucity, this analysis focuses on social and spatial inequalities in NI.

\section{Methods}

The methodology for this analysis follows the principles of reproducible research (see Koenker and Zeileis, 2009); that is the independent assessment and repeatability of analysis based on the careful documentation of the methodology and software used. Another aspect of the methodology was to use open source software, in this case the statistical software R, explained further in the software section. When analysing spatial data it is important to be familiar with the modifiable areal unit problem (MAUP; Openshaw, 1984) in order to ensure that proper account is taken of the potential for bias in analysis. Similarly, awareness of the 'ecological fallacy' (Robinson, 1950), that is inferences about areas (for example a gridsquare) do not necessarily mean that individuals within those areas have the same characteristics, is necessary. This means that the results will show the 'experience' of areas, but not of each and every individual within that area. To quantitatively assess patterns in the spatial data the Moran statistic (Cliff and Ord, 1981) was calculated, which is a summarisation of the spatial arrangement (or spatial autocorrelation) of the data. The Moran statistic is a measure of the influence of neighbouring spatial units and how this affects the values of variables observed in other neighbours. Positive spatial autocorrelation implies that there is clustering in the features of a particular dataset, that is to say neighbours are similar. If negative spatial autocorrelation is present, data is dissimilar to its neighbours. Positive values of the Moran statistic indicate positive spatial autocorrelation and negative values, negative spatial autocorrelation respectively. To sum up, consider the first law of geography,"everything is related to everything else, but near things are more closely related than distant things" (Tobler, 1970).

\section{Data}

The maps were produced to investigate the social structure of NI using a fine-grained spatial unit, the 1KGS. The 1KGS is both consistent through time (unlike many other areal boundaries) from 1971 to 2001 and underutilised for research, as few examples 
of its use exist. One such example is the work of Shuttleworth and Lloyd (2009) who state that "These data are unique; a similar dataset was generated from the 1971 GB Census but it was then discontinued" (p.215). This allows new perspectives on social and spatial inequalities to be observed and interpreted, although no use is made of the consistency through time in this analysis. The data used is licensed by the Economic and Social Research Council (ESRC) and made available to educational institutions in the UK via the EDINA UKBorders services (http://edina.ac.uk/ukborders/). The data was transformed by removing the items that had geographical restrictions (e.g. if a polygon was in the sea) or data restrictions (e.g potential disclosure).

The variables used for the analysis were manipulated from their original format to calculate rates of each 'indicator' mapped. Three indicators were constructed:

- Limiting Long Term Illness (LLTI): calculated by dividing the number of Persons with a Long Term Limiting Illness by the total population. This will give an idea of the proportion of people suffering from illnesses;

- Economic Activity (EA): calculated by summing Economically Active Males and Economically Active Females, then dividing by the total population. This indicator gives a summary of the level of economic activity of the population of an area; and

- No Qualifications (NQ): calculated by dividing the number of Persons with No Qualifications by the total population. This indicator aims to show the proportion of people in an area with no qualifications.

The indicators were then divided by total population and mapped by quintile. The final map is a combination of the quintiles of the three indicator, which shows multiple advantage or disadvantage respectively. The choice of classification used is 'quintile breaks' and therefore arbitrary; different classes will emphasize alternative aspects of the data. Quintiles were chosen to allow equal size classes to be displayed. The weakness of mapping with the 1KGS is that very small and rural areas are likely to be omitted because of disclosure constraints. This is a weakness of the 1KGS as it is arbitrary in its placement, as opposed to Output Areas for example, which try to include a minimum population. The advantage is the $1 \mathrm{KGS}$ reveals a more distinct picture of where people actually live. 


\section{Results}

The maps provide an indication of the clustering of the three indicators; LLTI, EA and NQ respectively, across NI. For those not familiar with the geography of NI, note that the large water mass in the middle of NI is Lough Neagh and the gaps to the south east are the Mourne mountains, the north east, the Antrim hills and to the west, the Sperrin mountains. This explains the lack of data in these areas. Keeping the geography in mind each 'indicator' map is discussed in turn, firstly economic activity, illness, qualifications and finally the combined map.

Low EA is focused in and around the north and west of Belfast, with EA increasing in a ring around the city. More generally, the west has lower EA than the east. NQ is clustered in urban areas, with the exception of an area of south Belfast (which includes student areas). There is also a large ring of people with qualifications around the Belfast urban area. Visually the pattern of LLTI is concentrated in the inner city of both Belfast and Londonderry. In addition, the west of NI has higher rates, in general, than the east of NI. All three indicators have an east-west split. Quantitatively, the Moran statistic (Table 1) indicates that LLTI is the least positively spatially autocorrelated, followed by EA then NQ and that all are significant. The fourth map, a combination of all three indicators, shows the 'worst' concentration in inner Belfast, with a ring of the 'best' around the edges of Greater Belfast. Elsewhere, a clear pattern is difficult to deduce.

\begin{tabular}{rrr} 
& Moran's I & p-value \\
\hline Moran.LLTI & 0.00005328701 & 0.00 \\
Moran.ECACT & 0.00005328701 & 0.00 \\
Moran.QUALS & 0.00005328701 & 0.00 \\
\hline
\end{tabular}

Table 1. Moran Statistics for 2001 Census data. Note 0.00 means “less than 0.005 . Moran's I positive values indicate positive spatial autocorrelation and negative values, negative spatial autocorrelation respectively.

\section{Conclusions}

In conclusion, the spatial variation of NI has been visualised using descriptive mapping of the 1KGS and quantified using the Moran statistic. There is an inherent bias against sparsely populated or rural areas which must be taken into account when considering the results. Also, it is important to bear in mind that classifying the data using 'quintile breaks' may visually emphasise different aspects of the data. The maps visually demonstrate which areas exhibit similar (or dissimilar) characteristics to neighbouring areas, formally tested at a global level using Moran's I. There are clear concentrations of the variables in the Belfast area of both 'good' clusters to the East and South (low rates 
of LLTI, NQ and high rates of EA) and 'bad' clusters in the North and West of the city. This is reflected at a country level as an East-West split of 'good', the areas to the Eastern side of NI and 'bad', occurring more on the Western side of NI. This demonstrates spatial inequalities at an intra-regional level. The combined 'indicator' map also shows pockets of poor 'performance' for all three indicators which could be used to help formulate social policy. Policy should therefore focus on reducing both the concentration of 'bad clusters' and the differences between the 'good' and 'bad' areas more generally.

\section{Software}

The software used for the spatial analysis in this short article was the open source statistical software R (R Development Core Team, 2007, http:/ /www.r-project.org), and the spatial data packages spdep (Bivand, 2008), maptools (Lewin-Koh and Bivand, 2008) and RColorBrewer (Neuwirth, 2007, http:/ / colorbrewer2.org/). The R software was used to input the data and to undertake any calculations required, principally the Moran Statistic and the mapping. $\mathrm{R}$ was also used to output maps to graphics files post analysis. RColorBrewer was used to colour the maps. The scripting code is available from the author.

\section{Acknowledgements}

Census statistics and boundary data for the 2001 One Kilometre Gridsquares is the EDINA hosted UKBorders. I am grateful to Dr Anyadike-Danes and Dr Shuttleworth for useful comments of an earlier version of this paper.

\section{References}

ACHESON, D. (1998) Independent inquiry into inequalities in health, Stationery Office.

BIVAND, R. (2008) spdep: Spatial dependence: weighting schemes, statistics and models [Online]. Available from: http://cran.r-project.org/web/packages/spdep/index.html, [Last accessed: 18 August, 2009].

BLACK, D., MORRIS, J., SMITH, C. and TOWNSEND, P. (1980) Inequalities in health: report of a Research Working Group, Department of Health and Social Security.

BOYLE, P., EXETER, D., FENG, Z. and FLOWERDEW, R. (2005) Suicide gap among young adults in Scotland: population study, British Medical Journal, 330, 175-176, doi:10.1136/bmj.38328.559572.55. 
CAMPBELL, R. (1993) Research into inequalities in health in Northern Ireland: What research?, Critical Public Health, 4, 5 - 8, doi:10.1080/09581599308406887.

CHRISTIE, B. (2001) Suicide rate in young men in Scotland is twice that in England and Wales, British Medical Journal, 323, 888, doi:10.1136/bmj.323.7318.888.

CLIFF, A. D. and ORD, J. K. (1981) Spatial processes : models \& applications, Pion, London.

DAVEY SMITH, G. (2003) Health inequalities : lifecourse approaches, Studies in poverty, inequality and social exclusion, Policy Press, Bristol.

DAVEY SMITH, G., DORLING, D., MITCHELL, R. and SHAW, M. (2002) Health inequalities in Britain: continuing increases up to the end of the 20th century, Journal of Epidemiology and Community Health, 56, 434-435, doi:10.1136/jech.56.6.434.

DAVEY SMITH, G., SHAW, M. and DORLING, D. (2001) Population change and mortality in men and women, Journal of Epidemiology and Community Health, 55, 9, doi:10.1136/jech.55.1.9.

DORLING, D. (1997) Death in Britain, Joseph Rowntree Foundation.

FERRIE, J. E., SHIPLEY, M. J., DAVEY SMITH, G., STANSFELD, S. A. and MARMOT, M. G. (2002) Change in health inequalities among British civil servants: the Whitehall II study, Journal of Epidemiology and Community Health, 56, 922-926, doi:10.1136/jech.56.12.922.

FRENCH, D. (2009) Residential segregation and health in Northern Ireland, Health and Place, 15, 888896, doi:doi:10.1016/j.healthplace.2009.02.012.

GJONCA, A., SMALLWOOD, S., TOMASSINI, C. and TOSON, B. (2005) Sex differences in mortality, a comparison of the United Kingdom and other developed countries, Health Statistics Quarterly, 26, 6-16.

GRAHAM, H. (2000) Understanding health inequalities, Open University Press, Buckingham.

HOWE, G. M. (1970) National atlas of disease mortality in the United Kingdom, Nelson, London.

KOENKER, R. and ZEILEIS, A. (2009) On reproducible econometric research, Journal of Applied Econometrics, 24, 833-847.

KRUGER, D. and NESSE, R. (2004) Sexual selection and the male: female mortality ratio, Evolutionary Psychology, 2, 66-85.

LEWIN-KOH, N. J. and BIVAND, R. (2008) maptools: Tools for reading and handling spatial objects [Online]. Available from: http:/ / cran.r-project.org/web/packages/maptools/index.html, [Last accessed: 18 August, 2009].

MARTIKAINEN, P. T. and VALKONEN, T. (1996) Excess mortality of unemployed men and women during a period of rapidly increasing unemployment, The Lancet, 348, 909-912, doi:10.1016/ S0140-6736(96)03291-6.

MCCARRON, P. G., DAVEY SMITH, G. and WOMERSLEY, J. J. (1994) Deprivation and mortality in Glasgow: changes from 1980 to 1992, British Medical Journal, 309, 1481-1482.

MITCHELL, R., DORLING, D. and SHAW, M. (2000) Inequalities in life and death: what if Britain were more equal?, Policy Press, Bristol. 
MORRIS, J. K., COOK, D. G. and SHAPER, A. G. (1994) Loss of employment and mortality, British Medical Journal, 308, 1135-1139.

NEUWIRTH, E. (2007) RColorBrewer: ColorBrewer palettes [Online]. Available from: http://cran. r-project.org/web/packages/RColorBrewer/index.html, [Last accessed: 18 August, 2009], r package version 1.0-2.

OPENSHAW, S. (1984) The Modifiable Areal Unit Problem, Concepts and Techniques in Modern Geography 38, GeoBooks, Norwich.

O'REILLY, D., BROWNE, S., JOHNSON, Z. and KELLY, A. (2001) Are cities becoming more unhealthy? An analysis of mortality rates in Belfast and Dublin between 1981 and 1991 to illustrate a methodological difficulty with ecological studies, Journal of Epidemiology and Community Health, 55, 354-355, doi:10.1136/jech.55.5.354.

O'REILLY, D. and STEVENSON, M. (1998) The two communities in Northern Ireland: deprivation and ill health, Journal of Public Health, 20, 161-168.

O'REILLY, D. and STEVENSON, M. (2003) Mental health in Northern Ireland: have the Troubles made it worse?, Journal of Epidemiology and Community Health, 57, 488-492, doi:10.1136/jech.57.7.488.

R DEVELOPMENT CORE TEAM (2007) R: A Language and Environment for Statistical Computing, R Foundation for Statistical Computing, Vienna, Austria, ISBN 3-900051-07-0.

RIGBY, J. E. and DORLING, D. (2007) Mortality in relation to sex in the affluent world, Journal of Epidemiology and Community Health, 61, 159-164, doi:10.1136/jech.2006.047381.

ROBINSON, W. S. (1950) Ecological Correlations and the Behavior of Individuals, American Sociological Review, 15, 351-357.

SHAW, M., DORLING, D., GORDON, D. and DAVEY-SMITH, G. (1999) The widening gap: health inequalities and policy in Britain, Studies in poverty, inequality and social exclusion, Policy Press, Bristol.

SHORTT, N. and RUGKÅSA, J. (2007) The walls were so damp and cold fuel poverty and ill health in Northern Ireland: Results from a housing intervention, Health and Place, 13, 99 - 110, doi:DOI:10. 1016/j.healthplace.2005.10.004.

SHUTTLEWORTH, I. G. and LLOYD, C. D. (2009) Are Northern Ireland's communities dividing? Evidence from geographically consistent Census of Population data, 1971 - 2001, Environment and Planning A, 41, 213-229, doi:10.1068/a40163.

SRIDHARAN, S., TUNSTALL, H., LAWDER, R. and MITCHELL, R. (2007) An exploratory spatial data analysis approach to understanding the relationship between deprivation and mortality in Scotland, Social Science and Medicine, 65, 1942-1952, doi:10.1016/j.socscimed.2007.05.052.

TOBLER, W. R. (1970) A Computer Movie Simulating Urban Growth in the Detroit Region, Economic Geography, 46, 234-240, doi:10.2307/143141.

TOWNSEND, P. and DAVIDSON, N. (1982) Inequalities in health: the Black Report, Penguin, Harmondsworth.

TOWNSEND, P., PHILLIMORE, P. and BEATTIE, A. (1988) Health and deprivation: inequality and the north, Croom Helm, London. 
WALSH, D., TAULBUT, M. and HANLON, P. (2008) The Aftershock of Deindustrialisation, Glasgow Centre for Population Health and NHS Health Scotland. 